Journal of Applied Pharmaceutical Science Vol. 4 (01), pp. 123-127, January, 2014

Available online at http://www.japsonline.com

DOI: $10.7324 / \mathrm{JAPS} .2014 .40121$

ISSN 2231-3354 (cc) BY-NC-SA

\title{
I n vitro evaluation of antifungal activity of aerial parts of medicinal plants Balanites aegyptiaca Del. and Spi lanthes acmella Murr.
}

\author{
Razia Khatoon ${ }^{1,2^{*}}$, Noor Jahan ${ }^{1,2}$, Siraj Ahmad ${ }^{3}$, Anwar Shahzad $^{4}$ \\ ${ }^{1}$ Department of Microbiology, Era's Lucknow Medical College and Hospital, Lucknow-226003, India. ${ }^{2}$ Department of Microbiology, Jawaharlal Nehru \\ Medical College and Hospital, Aligarh Muslim University, Aligarh-202002, India. ${ }^{3}$ Department of Community Medicine, Teerthanker Mahaveer Medical \\ College and Research Centre, Teerthanker Mahaveer University, Moradabad-244001, India. ${ }^{4}$ Plant Biotechnology Laboratory, Department of Botany, \\ Aligarh Muslim University, Aligarh-202002, India.
}

\author{
ARTICLE INFO \\ Article history: \\ Received on: 18/09/2013 \\ Revised on: 31/10/2013 \\ Accepted on: 30/11/2013 \\ Available online: 30/01/2014 \\ Key words: \\ Balanites aegyptiaca, \\ Spilanthes acmella, \\ antifungal activity, agar well \\ diffusion, minimum \\ inhibitory concentration.
}

\begin{abstract}
Aqueous and alcoholic extracts of endangered medicinal plants Balanites aegyptiaca Del. and Spilanthes acmella Murr. were evaluated for antifungal potential against various pathogenic and opportunistic fungi by in vitro agar well diffusion method. All the alcoholic extracts showed wide range of activity against the tested fungi as compared to aqueous extracts which showed limited antifungal activity. The alcoholic extract of fruit of $B$. aegyptiaca showed good antifungal activity against most of the tested Candida species and few opportunistic fungi, whereas, alcoholic extract of flower head of $S$. acmella showed good activity not only against Candida species but also against most of the tested Aspergillus species. Minimum inhibitory concentrations (MIC) of the alcoholic extracts were determined by broth microdilution method. The MIC of alcoholic extract of B. aegyptiaca and $S$. acmella against tested fungi ranged from 3.05 to $24.0 \mu \mathrm{g} / \mathrm{ml}$ and 1.53 to $49.0 \mu \mathrm{g} / \mathrm{ml}$ respectively. The present study leads to conclusion that extracts of Balanites aegyptiaca and Spilanthes acmella contain good antifungal activity and thus could be used as alternative medicine in the treatment of various opportunistic and life threatening fungal infections especially in immunocompromised patients which otherwise pose problem of resistance to the currently used antifungal agents.
\end{abstract}

\section{INTRODUCTION}

The fungi cause opportunistic infections in immunocompromised patients like those suffering from AIDS, cancer, diabetes, or undergoing treatment with immunosuppressive agents after transplant surgeries. Amongst these, candidiasis has become a major public health problem as it is one of the leading causes of fungal infection in immune-suppressed population, particularly in AIDS patients leading to oropharyngeal and oesophageal candidiasis (Al Ashaal et al., 2010). A vast majority of synthetic antibiotics control the growth and development of microorganisms effectively, but they are highly toxic at their optimum dosage level (Reddy, 2009). Also, antibiotic usage for the prevention and treatment of infections in these high-risk patients leads to selection pressures resulting in.

\footnotetext{
* Corresponding Author

*Dr. Razia Khatoon, Department of Microbiology, Era's Lucknow Medical College and Hospital, Lucknow-226003, India. Email:-drrazia@rediffmail.com
}

the emergence and spread of resistant organisms (Panghal et al., 2011). This situation of increasing failure of chemotherapeutics and antibiotic resistance as well as the undesirable effects of certain antifungal agents has forced the researchers to search for new antimicrobial substance from various sources including medicinal plants (Phongpaichit et al., 2005; Parekh and Chanda, 2008). Antimicrobials of plant origin have proved to be effective in the treatment of several infectious diseases and also they produce fewer side effects as compared to the synthetic antimicrobials (Samy and Ignacimuthu, 2000).

Balanites aegyptiaca Del. an endangered medicinal plant belongs to family Zygophyllaceae. It is also known as 'desert date' in English and 'Hingoli' in Hindi. The plant is a small evergreen thorny tree found in drier parts of India and Africa (particularly in Sudan). It grows to $6-10 \mathrm{~m}$ in height, is highly resistant to stresses such as sandstorms and heat waves, and grows with minimal available moisture. The trees produce date-like fruits between March and October. 
All parts of this plant have medicinal properties and have been used as folk medicine in many regions of Africa and Asia. Literatures have revealed that bark, unripe fruits, and leaves of this plant have anthelminthic, antifertility, purgative, antifeedant, antidiabetic, molluscicide, contraceptive, anti-tumor and antidysenteric properties. Dried fruits of this plant are being used as abortifacient by local healers. This plant has also been used in treatment of various ailments such as stomach aches, syphilis, epilepsy, haemorrhoids, malaria, herpes zoster, and yellow fever (Mohamed et al., 2000; Ojo et al., 2006; Gaur et al., 2008; Gnoula et al., 2008).

Spilanthes acmella Murr. an endangered plant belongs to the family Asteraceae. It is a flowering herb native to Brazil, and is grown as an ornamental plant in various parts of the world. It is found throughout India, up to 5000 feet in the Himalayas and other mountains. Its growth peaks in November to March and requires frequent watering. It is commonly known as 'Akarkara' or 'toothache plant'.

The entire plant is medicinally active and non-toxic to humans. The Indian traditional healers use the flower heads of this plant in dental and gum care. It is one of the major ingredients in popular herbal tooth powders and paste. The flower heads and roots have been used for treatment of scabies, psoriasis, scurvy, toothache, infections of gums and throat, paralysis of tongue and as a remedy for stammering in children. Its extracts also possess properties which cause repair of functional wrinkles, hence it is used in anti-age creams. The leaves and flower heads contain analgesic, antifungal, anthelminthic, antimalarial, antibacterial, diuretic and immunostimulating activity (Ratnasooriya et al., 2004; Rani and Murty, 2006; Barman et al., 2009; Prachayasittikul et al., 2013).

The present study was carried out to evaluate the antifungal potential of medicinal plants Balanites aegyptiaca and Spilanthes acmella by testing their activity against an exhaustive range of fungal isolates, including both standard as well as clinical strains.

\section{MATERIALS AND METHODS}

\section{Collection of plant materials}

Fruit pulp of a 15 years old plant of Balanites aegyptiaca was obtained from Tissue culture Laboratory, Department of Botany, Gujarat University, Ahmedabad, and young flower head was collected from 4 months old plant of Spilanthes acmella grown in the Medicinal Plant Nursery of Tamnaar, Raipur, Chhattisgarh.

\section{Preparation of plant extracts}

Both aqueous and alcoholic extracts of the plants were tested for antifungal activity. The extracts were prepared according to the method of Singh and Singh (2000) with some modifications as described below. To prepare aqueous extracts, fresh fruit (15 g) of B. aegyptiaca and flower head (15 g) of $S$. acmella were taken and surface sterilized in $70 \%$ ethyl alcohol for $1 \mathrm{~min}$ and then washed 3 times with sterilized double distilled water (DDW). These were then grounded with sterilized pestle and mortar in 150 ml of DDW separately. The homogenized tissues were then centrifuged at $5000 \mathrm{rpm}$ for $15 \mathrm{~min}$ and the supernatant was filtered and taken as aqueous extract. Similarly, alcoholic extracts were prepared using $150 \mathrm{ml}$ of $95 \%$ ethanol in place of DDW. The extracts were immediately used for experimentation.

\section{Fungi Tested}

The clinical fungal strains tested were Candida albicans, Candida parapsilosis, Candida krusei, Aspergillus fumigatus, Aspergillus flavus, Aspergillus niger, Alternaria spp., Penicillium spp. and Fusarium spp. isolated from various clinical specimens in the Department of Microbiology, Jawaharlal Nehru Medical College and Hospital, Aligarh Muslim University, Aligarh, India. The fungal control strains included in our study were $C$. parapsilosis (ATCC 22019), C. krusei (ATCC 6258) and A. fumigatus (ATCC 204305), obtained from New Drug Discovery Research, Ranbaxy, Gurgaon, India. The fungi were grown at $25^{\circ} \mathrm{C}$ in biological oxygen demand incubator and maintained on Sabouraud's Dextrose agar slants.

\section{Antifungal susceptibility testing}

Antifungal activity of the extracts of these plants was determined on Sabouraud's Dextrose agar (SDA) plates by using agar well diffusion method (Akinpelu, 2001), with some modifications as described below. An inoculum size of $2 \times 10^{6}$ yeast cells or fungal spores was used for inoculating the susceptibility plates.

Two sets of SDA plates (one each for aqueous and alcoholic extracts) were lawn cultured with fungal suspensions with the help of sterile swabs. Wells of $5 \mathrm{~mm}$ diameter were made in each plate using a sterile borer. Plant extracts $(20 \mu 1)$ were poured in the wells using micropipette. Sterilized DDW and 95\% ethanol $(20 \mu \mathrm{l}$ each) were used as negative controls in the aqueous and alcoholic plates respectively. A broad spectrum antifungal agent voriconazole $(500 \mu \mathrm{g} / 20 \mu \mathrm{l})$ was used as positive control. The plates were kept upright for 5-10 min until the solution diffused into the medium and then incubated aerobically at $25^{\circ} \mathrm{C}$ in a biological oxygen demand (BOD) incubator for 2-5 days. Later, the zone of inhibition was measured and recorded. All experiments were performed in triplicate.

\section{Determination of minimum inhibitory concentrations (MIC)}

MICs of the alcoholic extracts were determined by broth micro-dilution method performed according to Clinical and Laboratory Standards Institute (CLSI), formerly known as National Committee for Clinical Laboratory Standards, NCCLS (1997) for yeasts and NCCLS (2002) for filamentous fungi. Doubling dilutions of the extracts were prepared using RPMI-1640 (HiMedia, India) broth supplemented with $0.3 \mathrm{~g} / \mathrm{L}$ L-glutamine (HiMedia, India), $0.165 \mathrm{~mol} / \mathrm{L}$ of 3 -[N-morpholino] propanesulfonic acid (MOPS) buffer (HiMedia, India) and $0.01 \%$ of Dimethyl sulphoxide (DMSO) (Qualigens Fine Chemicals, 
India). Extracts were dissolved in DMSO, and further diluted 1:50 in RPMI-1640 medium, and each resulting solution was used for a doubling dilution series. Microtitre plates were prepared containing $100 \mu \mathrm{l}$ of undiluted extracts in the first well, followed by doubling dilutions of extracts. The standardized inoculum of each fungal species was added to the respective dilution wells, including the first well.

The final concentrations of the extracts ranged from $25 \times$ $10^{3} \mu \mathrm{g} / \mathrm{ml}$ to $48 \times 10^{-3} \mu \mathrm{g} / \mathrm{ml}$. For each test there was a sterility control well containing alcoholic extract in RPMI-1640 broth plus DMSO and a growth control well containing fungal suspension without alcoholic extract. The microtitre plates were incubated at $35^{\circ} \mathrm{C}$ for 48 hours with their upper surface covered by sterile sealers. The lowest concentration of the extract that did not show any visible growth of the tested fungal species was considered the MIC of the extract for that fungus. All the MIC experimentations were performed in duplicate.

\section{Statistical analysis}

All the experiments of antifungal susceptibility testing were performed in triplicate. The results were expressed as the mean \pm standard error (SE). Data were analyzed statistically by one way analysis of variance (ANOVA) followed by Tukey's multiple analysis test (SPSS Software, Chicago, III, version 10). P values were calculated by one-sample T-test and $\mathrm{P}<0.05$ was considered statistically significant.

\section{RESULTS AND DISCUSSION}

Antifungal activities of aqueous as well as alcoholic extracts of fruit of $B$. aegyptiaca and flower head of $S$. acmella against the tested fungal species are shown in Table 1 and 2 respectively. Amongst the negative controls used, sterilized DDW did not show any zone of inhibition, whereas, absolute ethanol showed the zone of inhibition in the range of 0.00 to $8.67 \pm 0.33$ $\mathrm{mm}$. Positive control (voriconazole) showed the zone of inhibition in the range of $9.33 \pm 0.33$ to $13.00 \pm 0.58 \mathrm{~mm}$. Alcoholic extracts of both the plants showed better antifungal activity as compared to their aqueous extracts. The alcoholic fruit extract of B. aegyptiaca showed significant antifungal activity $(\mathrm{P}<0.05)$ against Candida albicans $\quad(\mathrm{P}=0.003), \quad$ Candida parapsilosis $\quad(\mathrm{P}=0.012)$ and Penicillium spp. ( $\mathrm{P}=0.017)$, and its $\mathrm{MIC}$ ranged from 3.05 to 24.0 $\mu \mathrm{g} / \mathrm{ml}$ (Figure 2).

The aqueous fruit extract of $B$. aegyptiaca showed mild but significant activity against Candida albicans $(\mathrm{P}=0.038)$ and Penicillium spp. $(\mathrm{P}=0.024)$. It is interesting to note that extracts of $B$. aegyptiaca effectively controlled the growth of most of the organisms which are important fungal pathogens responsible for causing opportunistic fungal infections in immune compromised patients especially those suffering from AIDS.

Various studies have been done previously by different researchers to analyze the antifungal potential of $B$. aegyptiaca (Al Ashaal, 2010; Panghal et al., 2011). They showed significant antifungal activity of this plant against Candida albicans, this supports our present research findings. On the other hand a study done by Abdallah et al.,(2012) showed significant antifungal activity of this plant against Aspergillus niger and Fusarium species. These findings are in contrast with our study. This variation in findings could be due to different concentrations of extracts used in their study as well as variation in active metabolites present in plant extracts derived from different places.

The alcoholic extract of flower head of $S$. acmella showed significant $(\mathrm{P}<0.05)$ activity against Candida krusei $(\mathrm{P}=0.007)$, Candida parapsilosis $(\mathrm{P}=0.005)$, Aspergillus fumigatus $(\mathrm{P}=0.012)$, Aspergillus niger $(\mathrm{P}=0.027)$ and Fusarium spp. ( $\mathrm{P}=0.038$ ), and its MIC ranged from 1.53 to $49.0 \mu \mathrm{g} / \mathrm{ml}$ (Figure 3). Aqueous extract of flower head of $S$. acmella showed significant antifungal activity against Candida krusei $(\mathrm{P}=0.024)$ and Aspergillus fumigatus $(\mathrm{P}=0.038)$. One may note that the organisms which are found to be susceptible to the extracts of $S$. acmella are important pathogens responsible for causing opportunistic fungal infections such as Aspergilloma (fungal ball) in patients suffering from pulmonary tuberculosis and carcinoma lung, thus increasing the problem of treatment of such high-risk patients.

Few studies have been conducted in the past to evaluate the antifungal potential of Spilanthes acmella (Phongpaichit et al., 2005; Rani and Murty, 2006). They showed significant activity of extract of Spilanthes acmella against Aspergillus niger and Fusarium species but no activity against Candida albicans. This supports our present research findings.
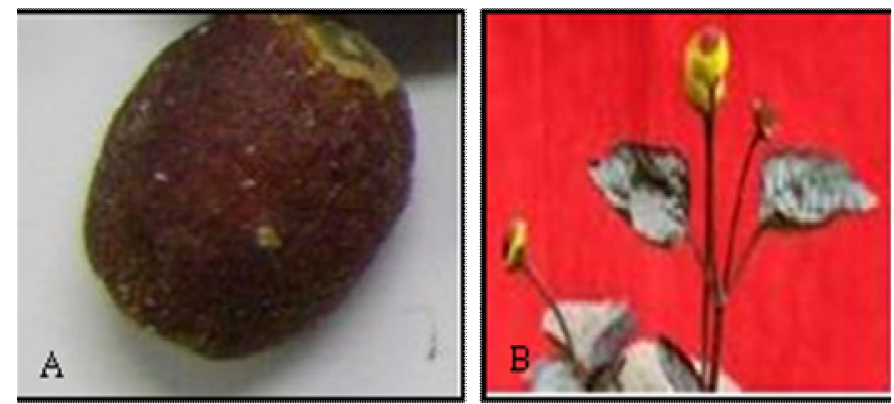

Fig. 1: shows various plant materials included in our study. A) Fruit of Balanites aegyptiaca and B) Flower of Spilanthes acmella.

\section{CONCLUSION}

In nutshell, alcoholic extracts of Balanites aegyptiaca and Spilanthes acmella contain remarkable antifungal potentials against most of the important fungal pathogens responsible for causing life threatening opportunistic fungal infections in immune-suppressed patients such as those suffering from immunodeficiency diseases, cancer, diabetes and AIDS. Though synthetic antibiotics have been developed for their treatment but at optimum dosage level these antifungal agents usually produce undesirable side effects. Also, resistance to even newly synthesized antifungal agents is on rise. Hence, in future extracts derived from both these plants may be used as novel antifungal agents. As these are herbal in nature, they may be more easily affordable and quite acceptable to such vulnerable patients. 
Table. 1: Antifungal activity of Balanites aegyptiaca against pathogenic and opportunistic Fungi.

\begin{tabular}{|c|c|c|c|c|c|}
\hline \multirow[b]{2}{*}{ Fungi tested } & \multicolumn{5}{|c|}{ Zone of inhibition $(\mathrm{mm}) \pm \mathrm{SE}$} \\
\hline & $\begin{array}{c}\text { Alcoholic fruit } \\
\text { extract }^{\Delta}\end{array}$ & $\begin{array}{c}\text { Aqueous fruit } \\
\text { extract }^{\Delta}\end{array}$ & $\begin{array}{c}\text { DDW }^{\dagger} \\
\text { (negative control) }\end{array}$ & $\begin{array}{c}\text { Ethanol }^{\dagger} \quad \text { (negative } \\
\text { control) }\end{array}$ & $\begin{array}{c}\text { Voriconazole }^{£} \\
\text { (positive control) }\end{array}$ \\
\hline Candida albicans & $15.33 \pm 0.67^{\mathrm{a}}$ & $14.67 \pm 0.33^{\mathrm{a}}$ & $0.00 \pm 0.00^{\mathrm{a}}$ & $8.33 \pm 0.33^{\mathrm{b}}$ & $12.33 \pm 0.33^{\mathrm{b}}$ \\
\hline Candida krusei & $0.00 \pm 0.00^{\mathrm{d}}$ & $0.00 \pm 0.00^{\mathrm{c}}$ & $0.00 \pm 0.00^{\mathrm{a}}$ & $7.67 \pm 0.33^{\mathrm{c}}$ & $11.67 \pm 0.33^{\mathrm{c}}$ \\
\hline Candida parapsilosis & $14.67 \pm 0.33^{\mathrm{ab}}$ & $0.00 \pm 0.00^{\mathrm{c}}$ & $0.00 \pm 0.00^{\mathrm{a}}$ & $8.67 \pm 0.33^{\mathrm{a}}$ & $12.67 \pm 0.33^{\mathrm{ab}}$ \\
\hline Aspergillus fumigatus & $0.00 \pm 0.00^{\mathrm{d}}$ & $0.00 \pm 0.00^{\mathrm{c}}$ & $0.00 \pm 0.00^{\mathrm{a}}$ & $7.67 \pm 0.33^{\mathrm{c}}$ & $10.33 \pm 0.33^{\mathrm{de}}$ \\
\hline Aspergillus flavus & $0.00 \pm 0.00^{\mathrm{d}}$ & $0.00 \pm 0.00^{\mathrm{c}}$ & $0.00 \pm 0.00^{\mathrm{a}}$ & $7.33 \pm 0.33^{\mathrm{d}}$ & $9.67 \pm 0.33^{\mathrm{e}}$ \\
\hline Aspergillus niger & $0.00 \pm 0.00^{\mathrm{d}}$ & $0.00 \pm 0.00^{\mathrm{c}}$ & $0.00 \pm 0.00^{\mathrm{a}}$ & $0.00 \pm 0.00^{\mathrm{e}}$ & $9.33 \pm 0.33^{\mathrm{f}}$ \\
\hline Alternaria spp. & $0.00 \pm 0.00^{\mathrm{d}}$ & $0.00 \pm 0.00^{\mathrm{c}}$ & $0.00 \pm 0.00^{\mathrm{a}}$ & $0.00 \pm 0.00^{\mathrm{e}}$ & $9.67 \pm 0.33^{\mathrm{e}}$ \\
\hline Penicillium spp. & $13.00 \pm 0.58^{\mathrm{c}}$ & $12.67 \pm 0.33^{\mathrm{b}}$ & $0.00 \pm 0.00^{\mathrm{a}}$ & $8.33 \pm 0.33^{\mathrm{b}}$ & $11.67 \pm 0.33^{\mathrm{c}}$ \\
\hline Fusarium spp. & $0.00 \pm 0.00^{\mathrm{d}}$ & $0.00 \pm 0.00^{\mathrm{c}}$ & $0.00 \pm 0.00^{\mathrm{a}}$ & $0.00 \pm 0.00^{\mathrm{e}}$ & $9.33 \pm 0.33^{\mathrm{f}}$ \\
\hline C. parapsilosis (ATCC 22019) & $14.33 \pm 0.33^{\mathrm{b}}$ & $0.00 \pm 0.00^{\mathrm{c}}$ & $0.00 \pm 0.00^{\mathrm{a}}$ & $8.67 \pm 0.33^{\mathrm{a}}$ & $13.00 \pm 0.58^{\mathrm{a}}$ \\
\hline C. krusei (ATCC 6258) & $0.00 \pm 0.00^{\mathrm{d}}$ & $0.00 \pm 0.00^{\mathrm{c}}$ & $0.00 \pm 0.00^{\mathrm{a}}$ & $8.33 \pm 0.33^{\mathrm{b}}$ & $12.33 \pm 0.33^{\mathrm{b}}$ \\
\hline A. fumigatus (ATCC 204305) & $0.00 \pm 0.00^{\mathrm{d}}$ & $0.00 \pm 0.00^{\mathrm{c}}$ & $0.00 \pm 0.00^{\mathrm{a}}$ & $7.67 \pm 0.33^{\mathrm{c}}$ & $10.67 \pm 0.33^{\mathrm{d}}$ \\
\hline
\end{tabular}

Table. 2: Antifungal activity of Spilanthes acmella against pathogenic and opportunistic Fungi.

\begin{tabular}{|c|c|c|c|c|c|}
\hline \multirow[b]{2}{*}{ Fungi tested } & \multicolumn{5}{|c|}{ Zone of inhibition $(\mathrm{mm}) \pm \mathrm{SE}$} \\
\hline & $\begin{array}{c}\text { Alcoholic flower } \\
\text { head extract } \Delta\end{array}$ & $\begin{array}{c}\text { Aqueous flower } \\
\text { head extract } \Delta\end{array}$ & $\begin{array}{c}\text { DDW } \dagger \\
\text { (negative control) }\end{array}$ & $\begin{array}{c}\text { Ethanol } \dagger \text { (negative } \\
\text { control) }\end{array}$ & $\begin{array}{c}\text { Voriconazole } £ \\
\text { (positive control) }\end{array}$ \\
\hline Candida albicans & $0.00 \pm 0.00 \mathrm{f}$ & $0.00 \pm 0.00 \mathrm{e}$ & $0.00 \pm 0.00 \mathrm{a}$ & $8.33 \pm 0.33 b$ & $12.33 \pm 0.33 \mathrm{~b}$ \\
\hline Candida krusei & $13.33 \pm 0.33 b c$ & $12.33 \pm 0.33 b$ & $0.00 \pm 0.00 \mathrm{a}$ & $7.67 \pm 0.33 c$ & $11.67 \pm 0.33 c$ \\
\hline Candida parapsilosis & $15.00 \pm 0.58 \mathrm{ab}$ & $0.00 \pm 0.00 \mathrm{e}$ & $0.00 \pm 0.00 \mathrm{a}$ & $8.67 \pm 0.33 \mathrm{a}$ & $12.67 \pm 0.33 \mathrm{ab}$ \\
\hline Aspergillus fumigatus & $12.33 \pm 0.33 \mathrm{~cd}$ & $11.00 \pm 0.58 \mathrm{~d}$ & $0.00 \pm 0.00 \mathrm{a}$ & $7.67 \pm 0.33 c$ & $10.33 \pm 0.33 \mathrm{de}$ \\
\hline Aspergillus flavus & $0.00 \pm 0.00 \mathrm{f}$ & $0.00 \pm 0.00 \mathrm{e}$ & $0.00 \pm 0.00 \mathrm{a}$ & $7.33 \pm 0.33 \mathrm{~d}$ & $9.67 \pm 0.33 \mathrm{e}$ \\
\hline Aspergillus niger & $11.33 \pm 0.33 d$ & $0.00 \pm 0.00 \mathrm{e}$ & $0.00 \pm 0.00 \mathrm{a}$ & $0.00 \pm 0.00 \mathrm{e}$ & $9.33 \pm 0.33 f$ \\
\hline Alternaria spp. & $0.00 \pm 0.00 \mathrm{f}$ & $0.00 \pm 0.00 \mathrm{e}$ & $0.00 \pm 0.00 \mathrm{a}$ & $0.00 \pm 0.00 \mathrm{e}$ & $9.67 \pm 0.33 \mathrm{e}$ \\
\hline Penicillium spp. & $0.00 \pm 0.00 \mathrm{f}$ & $0.00 \pm 0.00 \mathrm{e}$ & $0.00 \pm 0.00 \mathrm{a}$ & $8.33 \pm 0.33 b$ & $11.67 \pm 0.33 c$ \\
\hline Fusarium spp. & $10.67 \pm 0.33 \mathrm{e}$ & $0.00 \pm 0.00 \mathrm{e}$ & $0.00 \pm 0.00 \mathrm{a}$ & $0.00 \pm 0.00 \mathrm{e}$ & $9.33 \pm 0.33 f$ \\
\hline C. parapsilosis (ATCC 22019) & $15.33 \pm 0.33 \mathrm{a}$ & $0.00 \pm 0.00 \mathrm{e}$ & $0.00 \pm 0.00 \mathrm{a}$ & $8.67 \pm 0.33 a$ & $13.00 \pm 0.58 \mathrm{a}$ \\
\hline C. krusei (ATCC 6258) & $13.67 \pm 0.33 b$ & $12.67 \pm 0.33 a$ & $0.00 \pm 0.00 \mathrm{a}$ & $8.33 \pm 0.33 b$ & $12.33 \pm 0.33 b$ \\
\hline A. fumigatus (ATCC 204305) & $12.67 \pm 0.33 c$ & $11.33 \pm 0.33 c$ & $0.00 \pm 0.00 \mathrm{a}$ & $7.67 \pm 0.33 c$ & $10.67 \pm 0.33 \mathrm{~d}$ \\
\hline
\end{tabular}

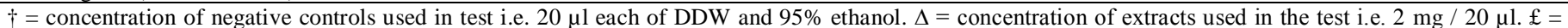

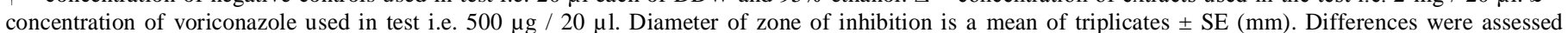

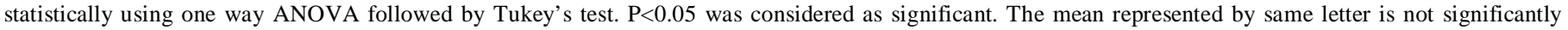
different within the column.

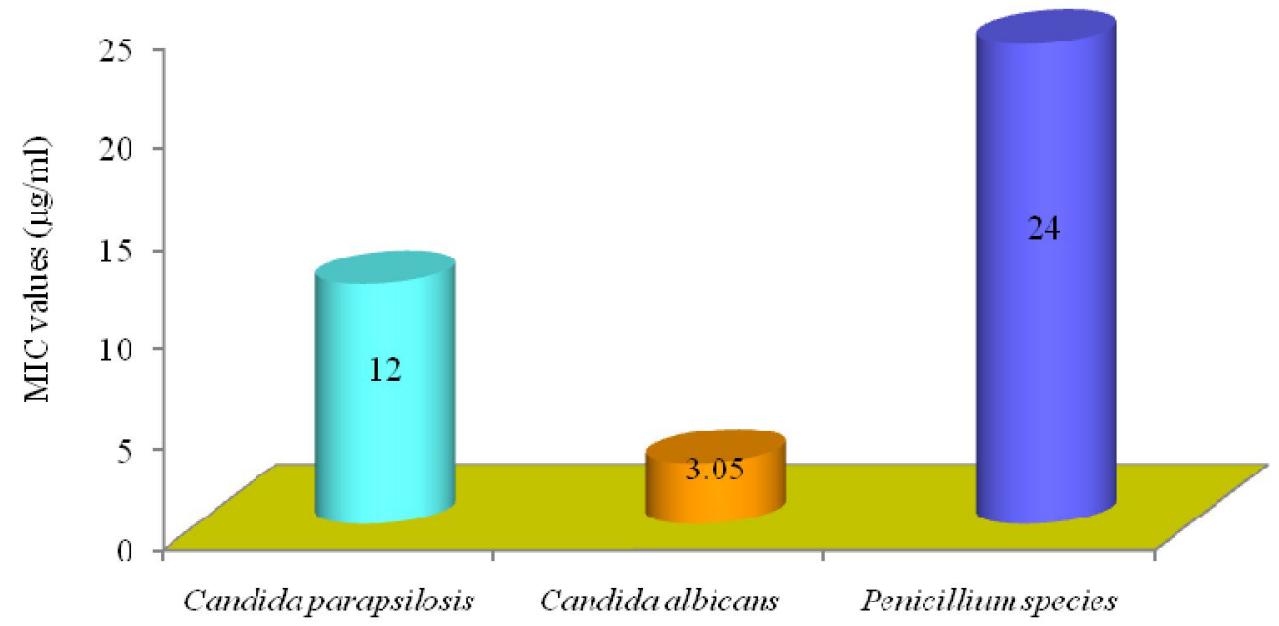

Fungal species tested

Fig. 2: MIC determination of alcoholic fruit extract of Balanites aegyptiaca against tested pathogenic and opportunistic fungi. 


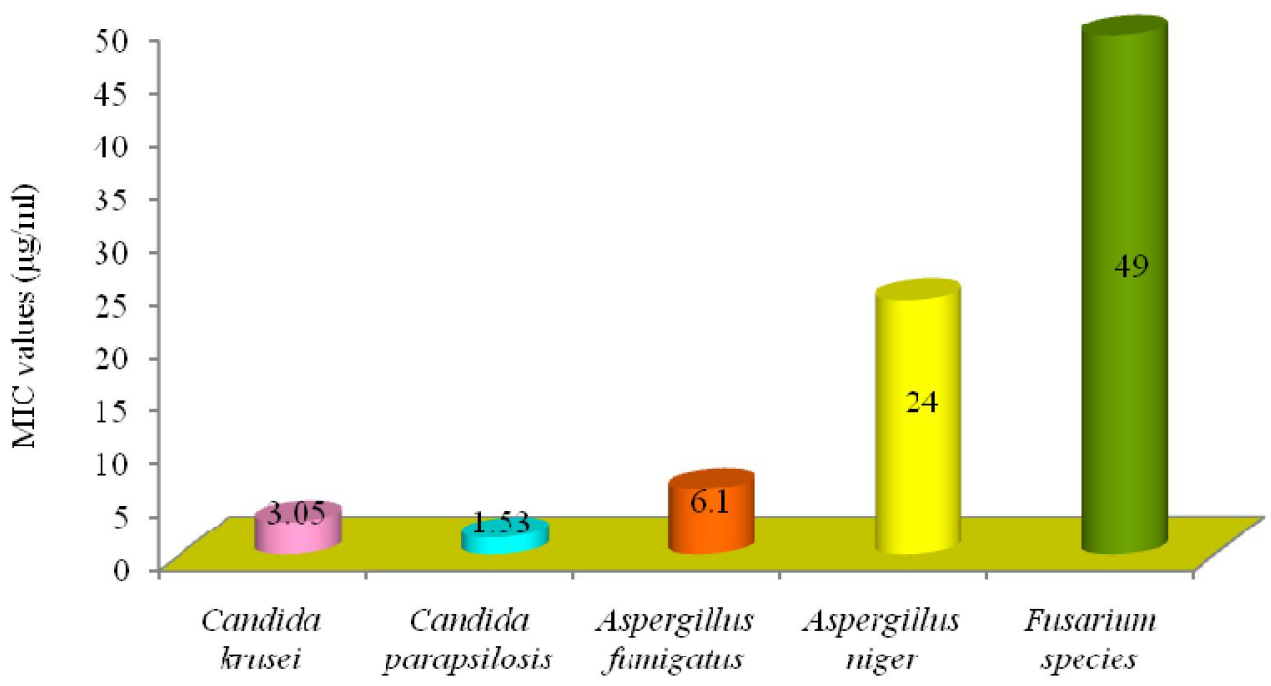

Fungal species tested

Fig. 3: MIC determination of alcoholic flower head extract of Spilanthes acmella against tested pathogenic and opportunistic fungi.

\section{REFERENCES}

Abdallah EM, Hsouna AB, Al-Khalifa KS. Antimicrobial, antioxidant and phytochemical investigation of Balanites aegyptiaca (L.) Del. edible fruit from Sudan. Afr J Biotechnol, 2012; 11: 11535-11542.

Akinpelu DA. Antimicrobial activity of Anacardium occidentale bark. Fitoterapia, 2001; 72: 286-287.

Al Ashaal HA, Farghaly AA, Abd El Aziz MM, Ali MA. Phytochemical investigation and medicinal evaluation of fixed oil of Balanites aegyptiaca fruits (Balantiaceae). J Ethnopharmacol, 2010; 127: 495-501.

Barman S, Sahu N, Deka S, Dutta S, Das S. Anti-inflammatory and analgesic activity of leaves of Spilanthes acmella (ELSA) in experimental animal models. Pharmacologyonline, 2009; 1: 1027-1034.

Gaur K, Nema RK, Kori ML, Sharma CS, Singh V. Antiinflammatory and analgesic activity of Balanites aegyptiaca in experimental animal models. Intern J Gr Pharm, 2008; 2: 214-217.

Gnoula C, Megalizzi V, Neve ND, Sauvage S, Ribaucour F, Guissou P, Duez P, Dubois J, Ingrassia L, Lefranc F, Kiss R, Mijatovik T. Balanitin-6 and -7: Diosgenyl saponins isolated from Balanites aegyptiaca Del. display significant anti-tumour activity in vitro and in vivo. Int $\mathrm{J}$ Oncol, 2008; 32: 5-15.

Mohamed AM, Wolf D, Spiess WE. Recovery and characterization of Balanites aegyptiaca Del. Kernel proteins: Effect of defatting, air classification, wet sieving and aqueous ethanol treatment on solubility, digestibility, amino acid composition and sapogenin content. Nahrung, 2000; 44: 7-12.

National Committee for Clinical Laboratory Standards (NCCLS). 1997. Reference method for broth dilution antifungal susceptibility testing of yeasts; approved standard. NCCLS Document M27-A5. NCCLS, Villanova, PA, US.

National Committee for Clinical Laboratory Standards (NCCLS). 2002. Reference method for broth dilution antifungal susceptibility testing for conidium-forming filamentous fungi; approved standard. NCCLS Document M38-A. Wayne, PA, USA.

Ojo OO, Nadro MS, Tella IO. Protection of rats by extracts of some common Nigerian trees against acetaminopheninduced hepatotoxicity. Afr J Biotechnol, 2006; 5: 755-760.
Panghal M, Kaushal V, Yadav JP. In vitro antimicrobial activity of ten medicinal plants against clinical isolates of oral cancer cases. Ann Clin Microbiol Antimicrob, 2011; 10: 21-32.

Parekh J, Chanda S. Antibacterial Activity of Aqueous and Alcoholic Extracts of 34 Indian Medicinal Plants against Some Staphylococcus Species. Turk J Biol, 2008; 32: 63-71.

Phongpaichit S, Subhadhirasakul S, Wattanapiromsakul C. Antifungal activities of extracts from Thai medicinal plants against opportunistic fungal pathogens associated with AIDS patients. Mycoses. 2005; 48: 333-338.

Prachayasittikul V, Prachayasittikul S, Ruchirawat S, Prachayasittikul V. High Therapeutic potential of Spilanthes acmella: A review. EXCLI Journal, 2013; 12: 291-312.

Rani SA, Murty SU. Antifungal potential of flower head extract of Spilanthes acmella Linn. Afri J Biomed Res, 2006; 9: 6768 .

Ratnasooriya WD, Pieris KPP, Samaratunga U, Jayakody JRAC. Diuretic activity of Spilanthes acmella flowers in rats. J Ethnopharmacol, 2004; 91: 317-320.

Reddy BU. Antimicrobial activity of Datura Stramonium L. and Tylophora indica (Burm.f.) Merr. Pharmacologyonline, 2009; 1: 1293 1300.

Samy RP, Ignacimuthu S. Antibacterial activity of some folklore medicinal plants used by tribals in western ghats of India. J. Ethnopharmacol, 2000; 69: 63-71.

Singh I, Singh VP. Antifungal properties of aqueous and organic extracts of seed plants against Aspergillus flavus and A. niger Phytomorphology, 2000; 50: 151-157.

\section{How to cite this article:}

Razia Khatoon, Noor Jahan, Siraj Ahmad, Anwar Shahzad., In vitro evaluation of antifungal activity of aerial parts of medicinal plants Balanites aegyptiaca Del. and Spilanthes acmella Murr. J App Pharm Sci, 2014; 4 (01): 123-127. 